Session 1268

\title{
Integrating Design Projects into an Introductory Course in Mechanics of Materials
}

\author{
David S. Cottrell, Stephen J. Ressler \\ United States Military Academy
}

\begin{abstract}
This paper describes the use of design projects in an introductory mechanics of materials course at the United States Military Academy. These projects serve to reinforce topics taught in the classroom and to introduce students to the engineering design process with their first hands-on design experience. Three representative examples of actual projects are presented. Students' end-of-course assessments are used to validate the effectiveness of the projects.
\end{abstract}

\section{Introduction}

In recent years, much has been written about the many potential benefits resulting from a freshman-level "Introduction to Engineering" or "Introduction to Design" course. Despite these benefits, however, many institutions have been unable to add such a course to their engineering curricula, for a variety of legitimate reasons. The United States Military Academy is one such institution. At USMA, all students take 31 common core courses, 16 of which are in the humanities. This substantial core curriculum leaves precious little room for the critical engineering topics necessary for maintaining viable, ABET-accredited engineering programs. In addition, our students do not select their academic major until their sophomore year and generally are not able to take any engineering courses until the second semester of that year. Thus a freshman "Introduction to Design" course is not a pragmatic option, and we must seek other vehicles for introducing our students to design at the earliest practical point in the curriculum.

This paper describes the use of design projects in an introductory mechanics of materials course at USMA. These projects serve not only to reinforce the topics taught in the classroom, but more importantly to introduce students to the engineering design process and to provide them with their first hands-on design experience.

The course is EM364A Mechanics of Materials, taken by all students majoring in civil and mechanical engineering, generally during the Fall semester of their junior year. For most of these students, EM364A is their second engineering course, but their first course with a design component. The course content is conventional, with coverage of internal forces, stress, strain, and deformations for various types of loading - axial, flexural, torsional, shear, and internal pressure. For each of these topics, however, the calculation of stresses and deformations is always taught within the context of their application to the analysis and design of actual structural components and systems. 
The practical application of course topics is highlighted and reinforced by three design projects, administered throughout the semester. The scenario and content of each project is keyed to the block of instruction being taught at the time. Though the specifics of these projects are changed each semester, their general content is as follows:

- The first project involves the design of axially loaded members in a simple structure, based on a specified allowable stress criterion.

- The second involves the design of a simple indeterminate structure, based on both allowable stress and allowable deformation criteria.

- The third involves the design of a more complex structure, subjected to combined loading.

The projects are structured to include — at an elementary level—all of the fundamental aspects of design, as defined in the ABET accreditation criteria. The projects are based on real-world scenarios, often involving actual construction or renovation projects in the West Point area; they are open-ended, permitting many possible solutions; they require the formulation of problem-solving methodologies and consideration of alternatives; they also require consideration of economic, ethical and social concerns related to the finished product. Students work on the projects in teams of 3 or 4, and are given approximately two weeks to develop their designs. The scope of the projects is sufficiently small to be achievable, but sufficiently complex to require a bona fide team effort to complete successfully. The product of each design is a formal design report, prepared in accordance with a standard format that specifies (1) a concise problem statement, (2) assumptions, (3) a description of the problemsolving approach, (4) the results of the design including sketches, charts, graphs, and discussion, and (5) recommendations to further improve the design.

In the paragraphs below, the authors describe the three design projects included in the most recent offering of EM364A. Due to space limitations, examples of student solutions are not included; however, the authors will provide copies of student solutions to interested mechanics educators upon request. 


\section{Project \#1: Truss Design}

This initial project builds on classroom instruction in normal stress and axially loaded members. Its principal purpose is to provide students with their very first design experience, as early in the course as possible. Students are placed in the role of design engineers developing a new parkway interchange system. Their assignment is to design the most economical overhead truss to support the weight of a suspended sign, as shown in Figure 1. Although the over all dimensions of the truss are

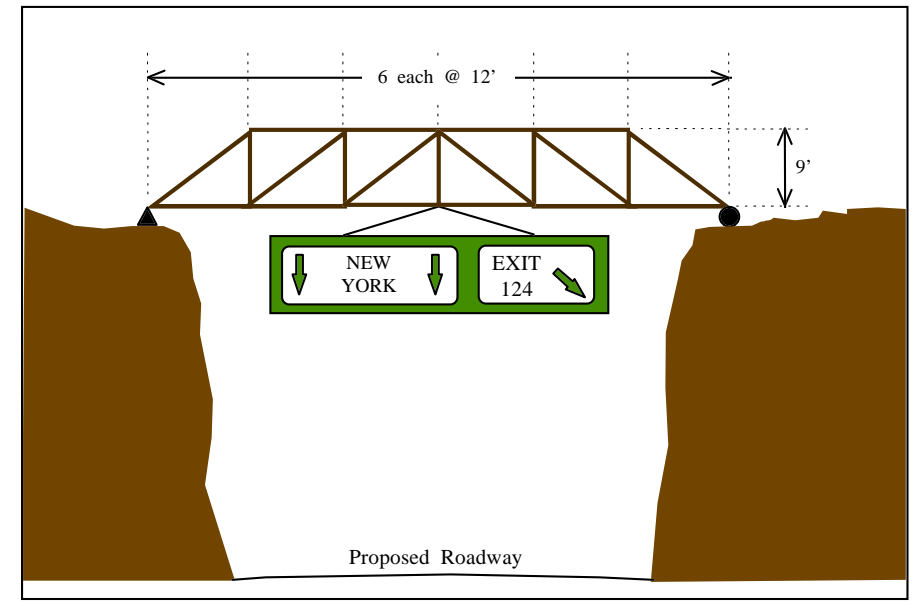

Figure 1. Truss Configuration prescribed, student designs can vary the geometric shape of the truss as well as investigate alternate methods for attaching the sign to the truss. The individual truss members can be either steel or aluminum bars, selected from a range of available sizes based on the designed structure and loading. Performance criteria specifies that the axial normal stress in the truss members cannot exceed an allowable stress (based on a factor of safety). Additionally, to enhance constructibility of the truss, structural members of the same length were also to have the same cross-sectional area. Their final report must recommend a configuration that produces an optimal distribution of internal forces in the structure. All alternative designs are assessed and compared in terms of their overall material cost.

\section{Project \#2: Elevated Track Structural Retrofit Design}

The scenario for this design project is based on the ongoing renovation of an athletic facility at West Point. Design teams are told that, as a result of the renovation, an elevated running track in one of the gymnasiums will have to be used as a temporary storage area. The track is suspended from the roof trusses of the gymnasium, as shown in Figure 2. As a result of its planned use as a storage area, the structure will be subjected to a considerably larger load than it was originally designed for. In particular, the wrought iron hanger rods are expected to be unsafe under the new loading. 
In this project, students serve as structural design consultants to West Point's Director of Public Works. They are assigned three tasks: (1) analyze the existing structure to verify that the hanger rods will indeed be unsafe under the new loading; (2) develop at least two different design concepts for supplemental bracing that will restore an adequate level of structural safety; and (3) recommend the best alternative design, based on cost and aesthetics. Because the actual structure is historically significant, students are prevented from specifying the removal or replacement of the existing hanger rods in their design. This aspect of the project accomplishes two purposes: it introduces a real-world architectural constraint, and it ensures that the students' redesigned structures will be statically

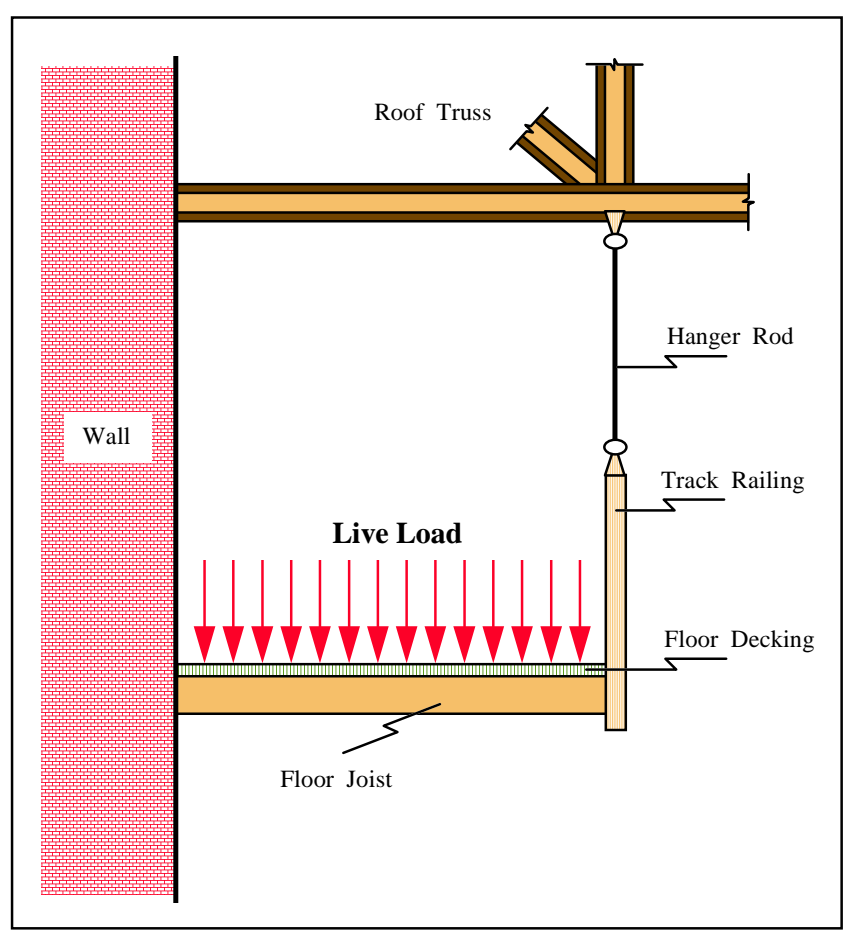

Figure 2. Elevated View of Elevated Track (As Built) indeterminate - a major objective of the project. A functional constraint is also specified. The supplemental bracing cannot interfere with the use of the elevated track or the gymnasium floor below. Since the project scenario is based on an actual, readily accessible structure, design teams are required to take field measurements for all critical dimensions. Two performance criteria are specified for the project. The stress in the existing hanger rod and the supplemental bracing cannot exceed an allowable stress (based on a factor of safety determined by the students), and the maximum deflection of the structure cannot exceed a specified allowable level.

\section{Project \#3: Composite Shaft and Gate Support System Design}

Assigned late in the semester, this third project requires students to design components of a more complex structural system, subjected to combined axial, flexural, and shear loading, as well as thermallyinduced deformations. Students are informed that the U. S. Army Corps of Engineers plans to extend the existing walls of a holding tank in order to allow greater capacity and better flexibility in controlling flood waters, as shown in Figure 3. The preliminary design calls for reinforcing the existing gate with a series of wide-flange beams. Students are required to complete the design by determining the optimum thickness of the steel plates in the composite shaft and the number and type of evenly spaced beams for the

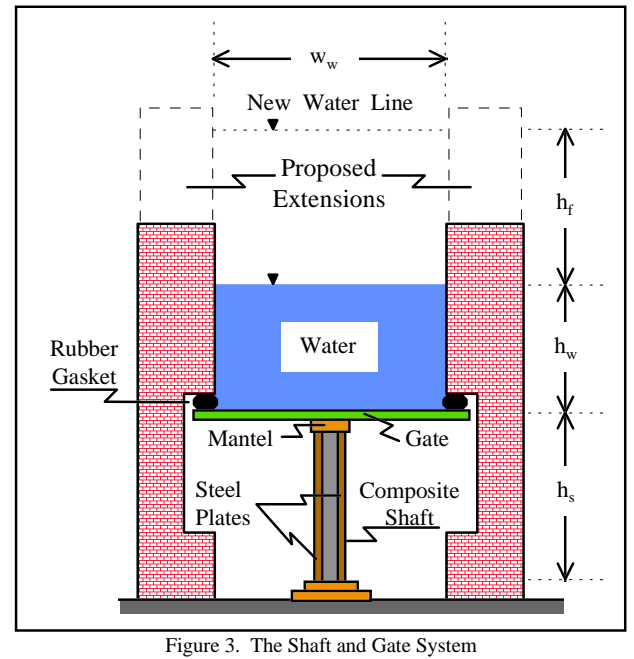

Figure 3. The Shaft and Gate System 
gate support system.

Performance criteria includes maximum allowable normal and shear stresses in all structural components for the composite shaft as well as the beams for the gate reinforcement system. Additionally, functional criteria stipulate a maximum deflection of the edge of the gate. A rubber gasket at the edge of the gate will not seal properly if the deflection exceeds a specified maximum. To satisfy this performance criterion, students must recognize that the deflection at the edge of the gate includes the combined effects of axial deformation of the shaft (due to both loading and seasonal temperature variation) and the flexural deformation of the gate, as shown in Figure 4. Alternative designs are assessed and compared in terms of their overall material cost for the composite shaft design and the beams of the gate support system.

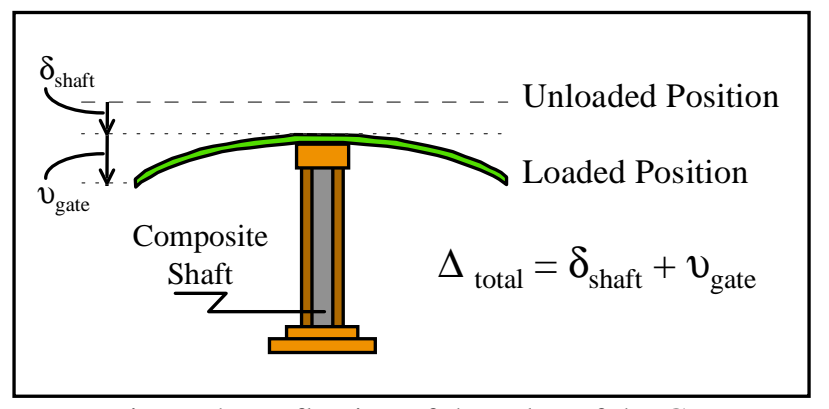

Figure 4. Deflection of the Edge of the Gate

\section{Conclusion}

Design projects like the three described above have been used successfully in EM364A for over ten years. During this period, the vast majority of student design teams have been able to complete the projects successfully, and many have developed insightful and highly creative solutions. Most of our students find the projects interesting, challenging, and enjoyable. On our most recent course-end critiques, $64 \%$ of the 90 students enrolled in the course rated the design projects as "very helpful" in promoting their understanding of the engineering design process. Another 34\% rated the projects as "helpful". Similarly, 89 of 90 reported that they felt "comfortable" or "very comfortable" with solving design problems, as a direct result of their experience with these projects. The authors have found the projects to be exceptionally effective in reinforcing course topics, in enhancing student-instructor interaction, and in stimulating students' interest in engineering.

As a result of our experience in EM364A, the authors conclude that: (1) it is indeed possible to integrate legitimate, realistic, open-ended design projects into an introductory mechanics of materials course, and (2) that these projects can serve as a viable introduction to the engineering design process in programs where a freshman-level introduction to design course is not feasible.

LIEUTENANT COLONEL DAVID S. COTTRELL is an Assistant Professor in the Department of Civil and Mechanical Engineering at USMA and is a registered Professional Engineer in Virginia. He graduated from the United States Military Academy in 1978 and received a Ph. D. degree from Texas A\&M University in 1995. He has taught courses in statics and dynamics and mechanics of materials.

LIEUTENANT COLONEL STEPHEN J. RESSLER is an Associate Professor and Director of the Civil Engineering Design Group, Department of Civil and Mechanical Engineering. A registered Professional Engineer, he received a Ph. D. degree from Lehigh University in 1991 and has taught courses in statics and dynamics, mechanics of materials, steel structures design, reinforced concrete, and structural systems design. 